Journal for ImmunoTherapy of Cancer

\title{
Phase II study of $\alpha$-galactosylceramide- pulsed antigen-presenting cells in patients with advanced or recurrent non-small cell lung cancer
}

\author{
Takahide Toyoda, ${ }^{1,2}$ Toshiko Kamata, ${ }^{1,2}$ Kazuhisa Tanaka, ${ }^{1}$ Fumie Ihara, ${ }^{1}$ \\ Mariko Takami, ${ }^{1}$ Hidemi Suzuki, ${ }^{2}$ Takahiro Nakajima, ${ }^{2}$ Takayuki Ikeuchi, ${ }^{3}$ \\ Yohei Kawasaki, ${ }^{4}$ Hideki Hanaoka, ${ }^{4}$ Toshinori Nakayama, ${ }^{5}$ Ichiro Yoshino, ${ }^{2}$ \\ Shinichiro Motohashi (D) ${ }^{1}$
}

To cite: Toyoda T, Kamata T, Tanaka K, et al. Phase II study of $\alpha$-galactosylceramidepulsed antigen-presenting cells in patients with advanced or recurrent non-small cell lung cancer. Journal for ImmunoTherapy of Cancer 2020;8:e000316. doi:10.1136/ jitc-2019-000316

- Additional material for this paper are available online. To view these files, please visit the journal online (http://dx.doi.org/ 10.1136/jitc-2019-000316).

Accepted 24 February 2020

\section{Check for updates}

(c) Author(s) (or their employer(s)) 2020. Re-use permitted under CC BY-NC. No commercial re-use. See rights and permissions. Published by BMJ.

${ }^{1}$ Department of Medical Immnunology, Graduate School of Medicine, Chiba University,

Chiba, Japan

${ }^{2}$ Department of General Thoracic Surgery, Graduate School of Medicine, Chiba University, Chiba, Japan

${ }^{3}$ Center for Advanced Medicine, Chiba University Hospital, Chiba, Japan

${ }^{4}$ Clinical Research Center, Chiba University Hospital, Chiba, Japan ${ }^{5}$ Department of Immnunology, Graduate School of Medicine, Chiba University, Chiba, Japan

Correspondence to

Shinichiro Motohashi;

motohashi@faculty.chiba-u.jp

\section{ABSTRACT}

Background Invariant natural killer T (iNKT) cells produce copious amounts of cytokines in response to specific glycolipid antigens such as $\alpha$-galactosylceramide ( $\alpha$ GalCer) presented by CD1d-expressing antigen-presenting cells (APCs), thus orchestrating other immune cells to fight tumors. Because of their ability to induce strong antitumor responses activated by $\alpha$ GalCer, iNKT cells have been studied for their application in cancer immunotherapy. In our previous phase I/I trial in non-small cell lung cancer (NSCLC) patients who had completed the standard treatment, we showed a relatively long median survival time without severe treatment-related adverse events. Based on these results, we performed a phase II trial to evaluate clinical responses, safety profiles and immune responses as a second-line treatment for advanced NSCLC.

Methods Patients with advanced or recurrent NSCLC refractory to first-line chemotherapy were eligible. $\alpha$ GalCerpulsed APCs were intravenously administered four times. Overall survival time was evaluated as the primary endpoint. The safety profile and immune responses after APC injection were also monitored. This study was an open label, singlearm, phase II clinical trial performed at Chiba University Hospital, Japan.

Results Thirty-five patients were enrolled in this study, of which $32(91.4 \%)$ completed the trial. No severe adverse events related to the treatment were observed. The estimated median survival time of the 35 cases was 21.9 months $(95 \% \mathrm{Cl}, 14.8$ to 26.0$)$. One case (2.9\%) showed a partial response, 14 cases $(40.0 \%)$ remained as stable disease, and 19 cases (54.3\%) were evaluated as progressive disease. The geometric mean number of iNKT cells in all cases was significantly decreased and the mean numbers of natural killer (NK) cells, interferon- $\gamma$-producing cells in response to $\alpha \mathrm{GalCer}$, and effector CD8+ T cells were significantly increased after the administration of $\alpha$ GalCerpulsed APCs.

Conclusions The intravenous administration of $\alpha$ GalCerpulsed APCs was well-tolerated and was accompanied by prolonged overall survival. These results are encouraging and warrant further evaluation in a randomized phase III trial to demonstrate the survival benefit of this immunotherapy. Trial registration number UMIN000007321.

\section{BACKGROUND}

Previously treated advanced or recurrent non-small cell lung cancer (NSCLC) cases are challenging to treat because the remaining treatment options are quite limited. Several immunotherapeutic approaches have been studied to determine better treatment options for cancer patients. ${ }^{1-3}$

CD1d-restricted invariant natural killer $\mathrm{T}$ (iNKT) cells are characterized by the expression of invariant $\mathrm{T}$ cell receptor (TCR), which recognizes a specific ligand, $\alpha$-galactosylceramide ( $\alpha$ GalCer). ${ }^{4} \mathrm{CD} 1 \mathrm{~d}$ is a major histocompatibility complex class I-like molecule that lacks heterogeneity and presents glycolipid antigens to iNKT cells. ${ }^{56}$ iNKT cells exhibit potent anti-tumor activity against various tumors through several mechanisms by recognizing glycolipid ligands presented on CD1d via TCRs. ${ }^{6-8}$ Activated iNKT cells become cytotoxic and produce high levels of cytokines including interferon- $\gamma$ (IFN$\gamma)$, thereby regulating innate and adaptive immune responses. ${ }^{9-11}$ Administration of $\alpha$ GalCer-pulsed dendritic cells (DCs) in multiple mouse models expanded iNKT cells and led to the eradication of established metastatic tumors. ${ }^{12} 13$ These findings have led to the development of NKT cell-targeted immunotherapy for treating cancer patients. Several clinical trials of NKT cell-targeted immunotherapy by us and other groups have shown promising results. ${ }^{14-18}$ Nieda et al. administered immature monocyte-derived DCs (MoDCs) with $\alpha$ GalCer pulse to cancer patients and observed activation of iNKT cells and their downstream activation of conventional $\mathrm{T}$ cells and NK cells. ${ }^{14}$ Chang et al. gave $\alpha$ GalCer-pulsed mature MoDCs to cancer patients and confirmed expansion 
of iNKT cells in vivo in humans. ${ }^{15}$ Whereas other groups use MoDCs as antigen-presenting cells (APCs), we established a new method of obtaining large numbers of APCs from peripheral blood mononuclear cells (PBMCs) and proposed that whole-cultured PBMCs instead of DCs had the potential to efficiently induce the expansion and activation of iNKT cells. ${ }^{19}$ We conducted several clinical studies of iNKT cell-targeted immunotherapy in patients with NSCLC and head and neck cancers. ${ }^{19-25}$ In a phase I/II clinical trial, in which 17 NSCLC patients who completed the standard treatment options were enrolled, the median survival time (MST) was relatively good at 18.6 months. ${ }^{22}$ Therefore, this treatment might be expected to lengthen the survival of patients with NSCLC or other cancers. Moreover, severe treatment-related adverse events were not observed in these trials, and thus the safety of this therapy is thought to be high. In addition, there is a possibility of maintaining the quality of life of patients with advanced NSCLC through the administration of this treatment. Because effective treatments have been limited to second-line treatment of NSCLC, it is important to explore the efficacy and safety of this treatment as a second-line therapy. From this point of view, we performed a phase II study of $\alpha$ GalCer-pulsed APC administration in patients with advanced NSCLC who had completed first-line treatment.

\section{METHODS}

\section{Patient eligibility criteria}

We included patients aged between 20 and 75 years with histologically or cytologically diagnosed NSCLC, and who had received platinum-based chemotherapy, as well as an appropriate tyrosine kinase inhibitor for those with an epidermal growth factor receptor (EGFR)-sensitizing mutation. Additional inclusion criteria were as follows: a performance status of 0 or 1 ; the existence of a measurable lesion; expected survival of 3 months or more; and had received no chemotherapy or radiotherapy for at least 4 weeks before enrollment. V $\alpha 24+\mathrm{V} \beta 11+$ iNKT cells were detected at a level of more than 10 cells in $1 \mathrm{~mL}$ peripheral blood by flow cytometry. Exclusion criteria included the following: a positive response to HIV, hepatitis $\mathrm{C}$ virus, or human $\mathrm{T}$ cell leukemia virus antibodies; positivity for hepatitis B surface antigen; the presence of active inflammatory disease or active autoimmune disease; a history of hepatitis; pregnancy or lactation; concurrent corticosteroid therapy; or evidence of another active malignant neoplasm. Histological type, staging, and the antitumor effect of the treatment were classified according to the seventh lung cancer tumor node metastases classification and staging system. ${ }^{26}$

\section{Clinical protocol and study design}

The study was an open label, single-arm, phase II clinical trial, and was undertaken in the Department of General Thoracic Surgery, Chiba University Hospital, Japan, according to the standards of Good Clinical Practice for Trials on Medicinal Products in Japan. The study was conducted in accordance with the Declaration of Helsinki.

A scheme of the study design is shown in figure 1 . Written informed consent was obtained from all patients before undergoing a screening evaluation to determine eligibility. Extensive clinical and laboratory assessments were conducted once a week and consisted of a complete physical examination and standard laboratory assessments. Adverse events and changes in laboratory values were graded according to the National Cancer Institute Common Terminology Criteria for Adverse Events V.3.0 (CTCAE). Patients were followed up for 2 years or until death.

\section{Preparation of APCs containing DCs from peripheral blood}

All procedures were performed according to Good Manufacturing Practice standards. Eligible patients underwent peripheral blood leukapheresis (COBE Spectra, Terumo BCT, Lakewood, CO), and PBMCs were separated by density gradient centrifugation (OptiPrep, Axis-Shield, Oslo, Norway). For the preparation of APCs containing DCs, PBMCs were cultured with GM-CSF and IL-2, as previously described. ${ }^{22}$ Briefly, PBMCs were washed three times and resuspended in AIM-V (ThermoFisher Scientific, Waltham, MA) with $800 \mathrm{U} / \mathrm{mL}$ human GM-CSF (GeneTech Co., Ltd, China) and $100 \mathrm{JRU} / \mathrm{mL}$ recombinant human IL-2 (Imunace; Shionogi, Japan). The cultured cells were pulsed with $200 \mathrm{ng} / \mathrm{mL} \alpha$ GalCer (KRN7000; REGiMMUNE, Japan) on the day before administration. After 7 or 14 days of culture, the cells were harvested, washed three times, and resuspended in $100 \mathrm{~mL} 2.5 \%$ albumin in saline. The criteria for $\alpha$ GalCerpulsed APC administration included a negative bacterial culture 48 hours before APC injection, cell viability of $>60 \%$, and an endotoxin test 48 hours before APC

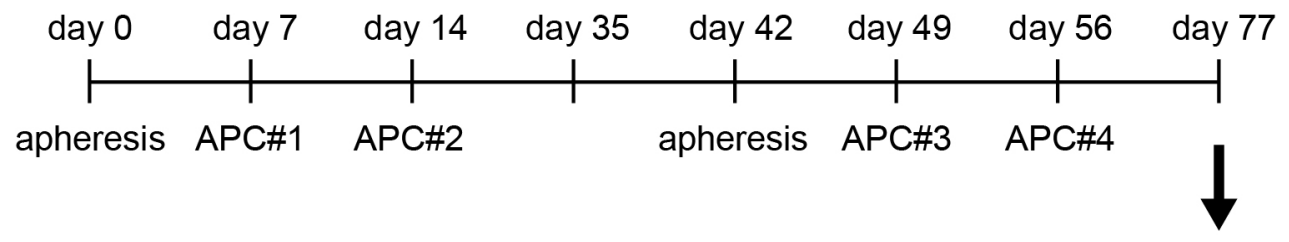

\section{2-year follow up}

Figure 1 Study design of $\alpha$ GalCer-pulsed APC administration. The patients received $\alpha$ GalCer-pulsed APCs containing DCs (APC\#1, APC\#2, APC\#3, and APC\#4). The timings of apheresis and APC administration are shown. $\alpha$ GalCer, $\alpha$-galactosylceramide; APCs, antigen-presenting cells; DCs, dendritic cells. 
injection with a result of $<0.7 \mathrm{EU} / \mathrm{mL}$. APCs containing DCs $\left(1 \times 10^{9}\right.$ cells $/ \mathrm{m}^{2} /$ injection) were administered four times intravenously (figure 1 ).

\section{Evaluation of APC phenotype}

The phenotypes of monocytes and APCs were determined with a FACSCanto II (BD Biosciences, Franklin Lakes, NJ) and FlowJo software (Flowjo, LLC, Ashland, OR). Monoclonal antibodies (mAbs) were as follows: fluorescein isothiocyanate (FITC)-labeled anti-HLA-DR, anti-CD14 (BD Biosciences), phycoerythrin (PE)-labeled anti-CD86, anti-CD1d (BD Biosciences), allophycocyanin-labeled anti-CD40 (BD Biosciences), and Pacific blue (PB)labeled anti-CD11c (Biolegend, San Diego, CA). Isotypematched control mAbs were used as negative controls.

\section{Identification of mononuclear cell fraction in peripheral blood}

PBMC samples were obtained from patients before the administration of $\alpha$ GalCer-pulsed APCs, and another eight times during the 11-week study period (figure 1). mAbs to detect and fractionate mononuclear cells in peripheral blood were: FITC-conjugated anti-TCR Vo24 (Beckman Coulter, Brea, CA), anti-CD14 (BD Biosciences), antiCD45RA (BD Biosciences), PE-conjugated anti-TCR V $\beta 11$ (Beckman Coulter), anti-CD56 (BD Biosciences), anti-CCR7 (Biolegend), allophycocyanin-conjugated antiCD3 (BD Biosciences), $\alpha$ GalCer-loaded CD1d tetramer (ProImmune), allophycocyanin-Cy7 conjugated antiCD3 (BD Biosciences), PE-Cy7-conjugated anti-CD8 (BD Biosciences), PB-conjugated anti-CD4 (BD Biosciences), anti-CD16 (BD Biosciences), anti-PD-1 (Biolegend), and anti-HLA-DR(Biolegend). The absolute numbers of these cells were also calculated using automated full blood counts.

\section{Single-cell enzyme-linked immunospot (ELISPOT) assay}

PBMCs were washed three times with PBS and then stored in liquid nitrogen until use. The detection of IFN- $\gamma$-secreting cells was performed as previously described. ${ }^{20}$ Briefly, 96-well filtration plates (Millipore, Bedford, MA) were coated with human anti-human IFN- $\gamma$ $\left(10 \mathrm{mg} / \mathrm{mL}\right.$, Mabtech, Sweden). PBMCs $\left(5 \times 10^{5} /\right.$ well $)$ were incubated for 16 hours with $\alpha$ GalCer $(200 \mathrm{ng} / \mathrm{mL})$ in $10 \%$ fetal bovine serum containing RPMI. Phorbol 12-myristate13-acetate $(10 \mathrm{mg} / \mathrm{mL})$ plus ionomycin $(10 \mathrm{nM})$ was used as a positive control. After culture, the plates were washed and incubated with biotinylated anti-IFN- $\gamma(1 \mathrm{mg} / \mathrm{mL}$, Mabtech). Spot-forming cells were quantified by microscopy.

\section{Evaluation of clinical responses and statistical analysis}

The primary endpoint was overall survival (OS; time from the first apheresis until death from any cause). Secondary endpoints were safety, progression-free survival (PFS), response rate (RR; percentage of patients with complete response (CR) or partial response (PR) as per RECIST V.1.1), and disease control rate (DCR; percentage of patients with CR, PR, or stable disease (SD)). OS, PFS, RR, DCR, and safety were analyzed in all patients who received at least one course of study treatment. Protocol deviation cases were excluded from the correlation analyses of immune responses and survival time because it would not be possible to adequately assess these without two courses of treatment. Because the MST of the previous phase I/II trial was 18.6 months, the expected survival time was determined to be 17 months. ${ }^{22}$ In addition, the threshold time was set to 8 months with reference to 7.8 months, which was the result of the MST of low-dose docetaxel monotherapy for NSCLC patients in Japan, ${ }^{27}$ the standard therapy for second-line treatment at the start of this study.

All patients underwent an assessment of tumor status by chest $\mathrm{CT}$ at baseline and 3 weeks after the fourth $\alpha \mathrm{GalCer}$ pulsed APC administration (11 weeks after study entry).

Continuous variables are summarized as the mean and SD and categorical variables as frequencies and proportions. The Kaplan-Meier method was used to estimate MST and a 95\% CI of OS and PFS. The difference between the good responders group and the poor responders group for OS was evaluated using a log-rank test. The linear mixed effect model for repeated measures was used to estimate the mean, $\mathrm{SE}$, and $95 \% \mathrm{CI}$ of the mean of each measuring point of immune monitoring, which can address all available post-baseline data. Safety was examined using the safety analysis set, which was defined as any patient who had received at least one dose and who had at least one safety assessment at post-baseline. A twosided p-value of $<0.05$ was considered statistically significant, and all analyses were performed using SAS V.9.4 for Windows.

\section{RESULTS}

\section{Patient characteristics}

A total of 35 patients were enrolled in the study from February 2012 to August 2015. Three patients became protocol deviation cases due to exacerbation of their primary disease within 4 weeks after administration of the therapy, and another treatment was prescribed. The characteristics of 35 patients who were enrolled in the trial are summarized in table 1 . The average age of these patients was 58.5 years. Six patients were clinical stage IIIB, 20 were stage IV, and nine were recurrent after surgical treatment. The study included 25 patients with adenocarcinoma, eight patients with squamous cell carcinoma, one patient with large cell carcinoma, and one patient with atypical carcinoid. All patients had received systemic first-line chemotherapy including platinum-based chemotherapy or EGFR tyrosine kinase inhibitor (TKI). Seven cases were positive for EGFR mutations, and five out of seven cases had received gefitinib as a primary treatment.

\section{Phenotype of APCs containing DCs}

The phenotype of APCs containing DCs prepared for each administration was analyzed by flow cytometry and is summarized in online supplementary table 1 . In all preparations, cultured cells exhibited an immature 
Table 1 Patient characteristics of all enrolled cases

Number of

cases (\%)

\begin{tabular}{lll}
\hline Age & Mean & 59.5 \\
Gender & Range & $38-75$ \\
& Male & $24(68.8)$ \\
Histology & Female & $11(31.3)$ \\
& Adenocarcinoma & $25(71.4)$ \\
& Squamous cell & $8(22.9)$ \\
& carcinoma & \\
Performance status & 0 & $1(2.9)$ \\
& Large cell carcinoma & $1(2.9)$ \\
Clinical staging & Atypical carcinoid & $3(8.6)$ \\
& C-stage IIIB & $32(91.4)$ \\
& C-stage IV & $6(17.1)$ \\
EGFR mutation & Recurrence & $20(57.1)$ \\
status & Wild & $9(25.7)$ \\
\hline Prior treatment & Mutation & $28(80)$ \\
& Platinum-based & $7(20)$ \\
& chemotherapy & $30(85.7)$ \\
& Gefitinib & $5(14.3)$ \\
& Surgery & $11(31.4)$ \\
& Radiation therapy & $11(31.4)$ \\
\hline
\end{tabular}

and mature MoDCs phenotype expressing HLA-DR and CD86. The expression levels of CD11c, CD1d, and CD40 were modest, while CD14 expression was low.

\section{Clinical outcome}

The primary endpoint was OS in the total population. All patients were followed up for 6.4 to 27.2 months to elucidate the prognosis and cause of death. The MST of all 35 cases was 21.9 months (95\% CI, 14.8 to 26.0 ). The 1 -year

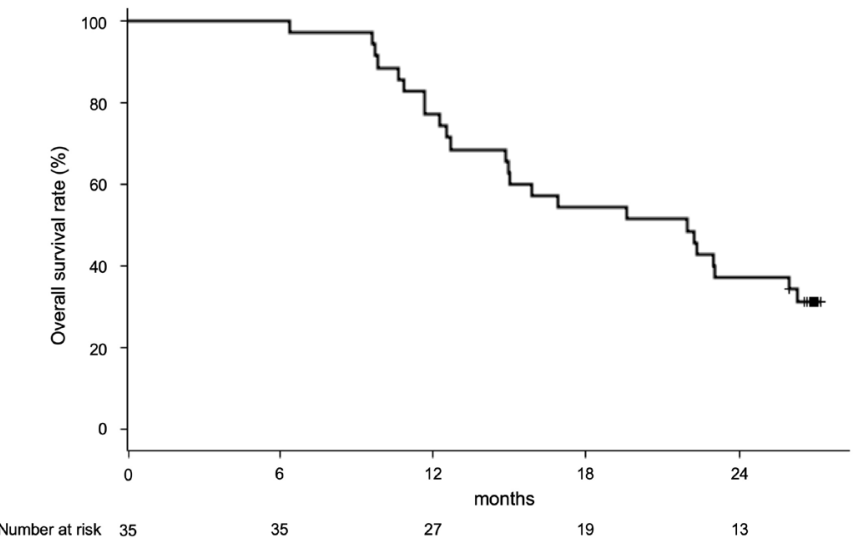

Figure 2 Overall survival of patients with $\alpha \mathrm{GalCer}-$ pulsed APCs. Overall survival curve of all patients treated with four rounds of $\alpha \mathrm{GalCer}-$ pulsed APCs. $\alpha \mathrm{GalCer}$, $\alpha$-galactosylceramide; APCs, antigen-presenting cells. survival rate was $84.4 \%$, and the 2-year survival rate was $40.6 \%$ (figure 2 ).

Antitumor response was evaluated by chest CT findings as described in table 2. There was one case of PR, 14 of $\mathrm{SD}, 19$ of progressive disease, and one that was unevaluable. RR was $2.9 \%$ and DCR was $42.9 \%$. The median PFS was 2.8 months (95\% CI, 2.6 to 3.7) and the rate of PFS at 1 year was $4.3 \%$.

\section{Adverse events}

Adverse events related to the treatment are listed in table 3. Nine out of 35 patients had treatment-related adverse events. All treatment-related adverse events were evaluated as grade 1 or 2 . Dysesthesia is associated with hypocalcemia in peripheral blood leukapheresis, and the symptoms disappeared immediately following the administration of calcium gluconate in this study. All grade 3 or 4 adverse events during the treatment are listed in online supplementary table 2 . One patient experienced worsening of tumor pain on day 15 (grade 3) and was admitted to the hospital for pain control. This patient had a metastatic tumor in the retroperitoneal space and morphine was prescribed before study enrollment due to back pain. The rapid enlargement of the mass induced worsening of tumor pain. Thus, no clear relationship between the cell therapy and tumor pain was established. No severe side effects were observed in the other patients.

Three patients experienced increased serum amylase levels (grade 3). Among these three patients, one patient showed grade 2 and two patients showed grade 1 serum amylase on study enrollment. No signs of pancreatitis or sialadenitis were detected, and no cases required additional treatment. One patient experienced grade 3 hypertension after the second apheresis, which occurred transiently. All adverse events that occurred during the treatment period are summarized in onlineonline supplementary table 3 .

\section{Immunological monitoring}

Immune monitoring was performed for 35 patients who received $\alpha$ GalCer-pulsed APC injections. PBMCs were fractionated, and each subset of immune cells was identified using mAbs and flow cytometry analysis. Figure 3 shows the results of the linear mixed models for repeated measurements of each immune cell number in all 35 cases. The absolute number of white blood cells and lymphocytes significantly increased after treatment; the geometric mean of white blood cells changed from $6.02 \times 10^{6}$ to $6.74 \times 10^{6}$ count $/ \mathrm{mL}$ and that of lymphocytes changed from $1.28 \times 10^{6}$ to $1.45 \times 10^{6} \mathrm{count} / \mathrm{mL}$ (all $\mathrm{p}<0.001$ ) (figure $3 \mathrm{~A}, \mathrm{~B}$ ). Moreover, the absolute number of V $\alpha 24+V \beta 11+$ iNKT cells significantly decreased after $\alpha$ GalCer-pulsed APC injection; the geometric mean of iNKT cells changed from $1.74 \times 10^{2}$ to $8.72 \times 10$ count $/ \mathrm{mL}$ $(\mathrm{p}<0.001)$ (figure 3C). The number of natural killer (NK) cells significantly increased; the geometric mean of NK cells was increased from $1.25 \times 10^{5}$ to $1.71 \times 10^{5}$ count $/ \mathrm{mL}$ $(\mathrm{p}<0.001)$ (figure 3D). While CD8+ T cells and effector 
Table 2 Tumor response rates

\begin{tabular}{lcccc}
\hline & Number & Rate (\%) & 95\% Cl lower & 95\% Cl upper \\
\hline Complete response & 0 & 0 & & \\
Partial response & 1 & 2.9 & & \\
Stable disease & 14 & 40.0 & & \\
\hline Progressive disease & 19 & 54.3 & & 14.9 \\
\hline Not evaluable & 1 & 2.9 & 0.1 & 60.7 \\
\hline Response rate & 1 & 2.9 & 26.3 & \\
\hline Disease control rate & 15 & 42.9 & & \\
\hline
\end{tabular}

memory CD8+ T cells did not increase, effector CD8+ $\mathrm{T}$ cells gradually increased from $5.40 \times 10^{4}$ to $6.67 \times 10^{4}$ count $/ \mathrm{mL}$ during the treatment period using all available data for each patient $(\mathrm{p}<0.01)$ (figure $3 \mathrm{E}-\mathrm{G})$. However, PD-1+CD8+ T cells did not change significantly.

Because our previous clinical study showed that increased IFN- $\gamma$-producing cells were associated with prolonged MST after $\alpha$ GalCer-pulsed APC injection, ${ }^{22}$ we assessed the ability of PBMCs to produce IFN- $\gamma$ after restimulation with $\alpha$ GalCer in vitro. The cryopreserved PBMCs were thawed and stimulated with $\alpha$ GalCer for 16 hours in vitro, and enzyme-linked immunospot assay assessed the number of IFN- $\gamma$-producing cells in the culture. As a result of the linear mixed model, IFN- $\gamma$-producing cells rapidly increased before the fourth $\alpha$ GalCer-pulsed APC administration and were back to the equivalent value of the pretreatment state 3 weeks after two cycles of the treatment (figure 4A). In 24 patients, the number of cells producing IFN- $\gamma$ increased more than 1.9-fold after the administration of $\alpha$ GalCerpulsed APCs (good responder: solid line in figure 4B). In the remaining eight patients, a minimal alteration $(<1.9)$ in the IFN- $\gamma$-producing capacity was observed (poor responder: dotted line in figure 4B). Among 35 cases, good responders exhibited a trend of longer survival (MST, 24.4 months; 95\% CI, 15.8-not estimable) compared with poor responders (MST, 14.9 months; 95\% CI, 9.6 to $22.9 ; \mathrm{p}=0.0656$ ) (figure $4 \mathrm{~B}$ ). The 2-year survival rate of the good responder group was $50.0 \%$ and that of the poor responder group was $12.5 \%$. iNKT cell number before treatment did not correlate with good immune responses or good prognosis (data not shown).

\begin{tabular}{lllll}
\hline \multirow{2}{*}{ Table 3 } & \multicolumn{3}{l}{ Treatment-related adverse events } \\
\cline { 2 - 3 } Event & \multicolumn{2}{l}{ First course } & \multicolumn{2}{l}{ Second course } \\
\cline { 2 - 3 } & \multicolumn{2}{l}{ Total number (\%) } & \multicolumn{2}{l}{ Total number (\%) } \\
\hline Fatigue & G1-G2 & G3-G5 & G1-G2 & G3-G5 \\
\hline Pain & $1(2.9)$ & 0 & $2(5.7)$ & 0 \\
Fever & $0(0.0)$ & 0 & $1(2.9)$ & 0 \\
Dysesthesia & $1(2.9)$ & 0 & $2(5.7)$ & 0 \\
\hline
\end{tabular}

\section{DISCUSSION}

This study aimed to explore OS after $\alpha$ GalCer-pulsed APC administration to patients with advanced or recurrent NSCLC who had completed first-line chemotherapy. We hypothesized that the expected survival time would be 17 months according to our previously reported data, ${ }^{22}$ and the threshold survival time would be 8 months by referencing a previous clinical trial. The median OS of all enrolled patients was 21.9 months, which was better than the expected survival time. Furthermore, the lower limit of the $95 \%$ CI of the MST (14.8 months) was longer than 8 months, which was set as the threshold MST, indicating that the MST would be extended by $\alpha$ GalCer-pulsed APC therapy. Although the RR of 2.9\% and the median PFS of 2.8 months was not impressive, the median OS of the study was promising in this cohort of pretreated patients. In recent clinical studies, two antiangiogenetic drugs (nintedanib and ramucirumab) in combination with docetaxel and three immune checkpoint inhibitors (nivolumab, pembrolizumab, and atezolizumab) showed a significant OS benefit over docetaxel, gaining approval as a second-line treatment. ${ }^{28-34}$ The MST of each cohort undergoing second-line therapy was 9.2-12.6 months for antiangiogenetic combination therapy and immunotherapy, while that for docetaxel was 6.0-9.7 months. ${ }^{28} 2931-33$ Because our study was a phase II trial and patient characteristics differed from other studies, these benefits should not be directly compared with those of any report. However, our results are encouraging and warrant further evaluation of the survival benefit of this immunotherapy, as the administration of $\alpha$ GalCer-pulsed APCs has the potential to constitute a new class of useful second-line treatment for advanced NSCLC.

Regarding safety, no serious treatment-related adverse events were experienced. Tumor pain occurred in one patient who had a progressive metastatic lesion just adjacent to the iliopsoas muscle. While hospitalization was needed to control the pain with morphine and palliative radiotherapy, the patient recovered to their preenrolled status within 2 weeks. This event was concluded to be unrelated to the current cell therapy since the pain was due to the rapid progression of the metastatic tumor. Thus, taken together with the results of a previous report, ${ }^{22}$ we concluded that the current procedure for the 

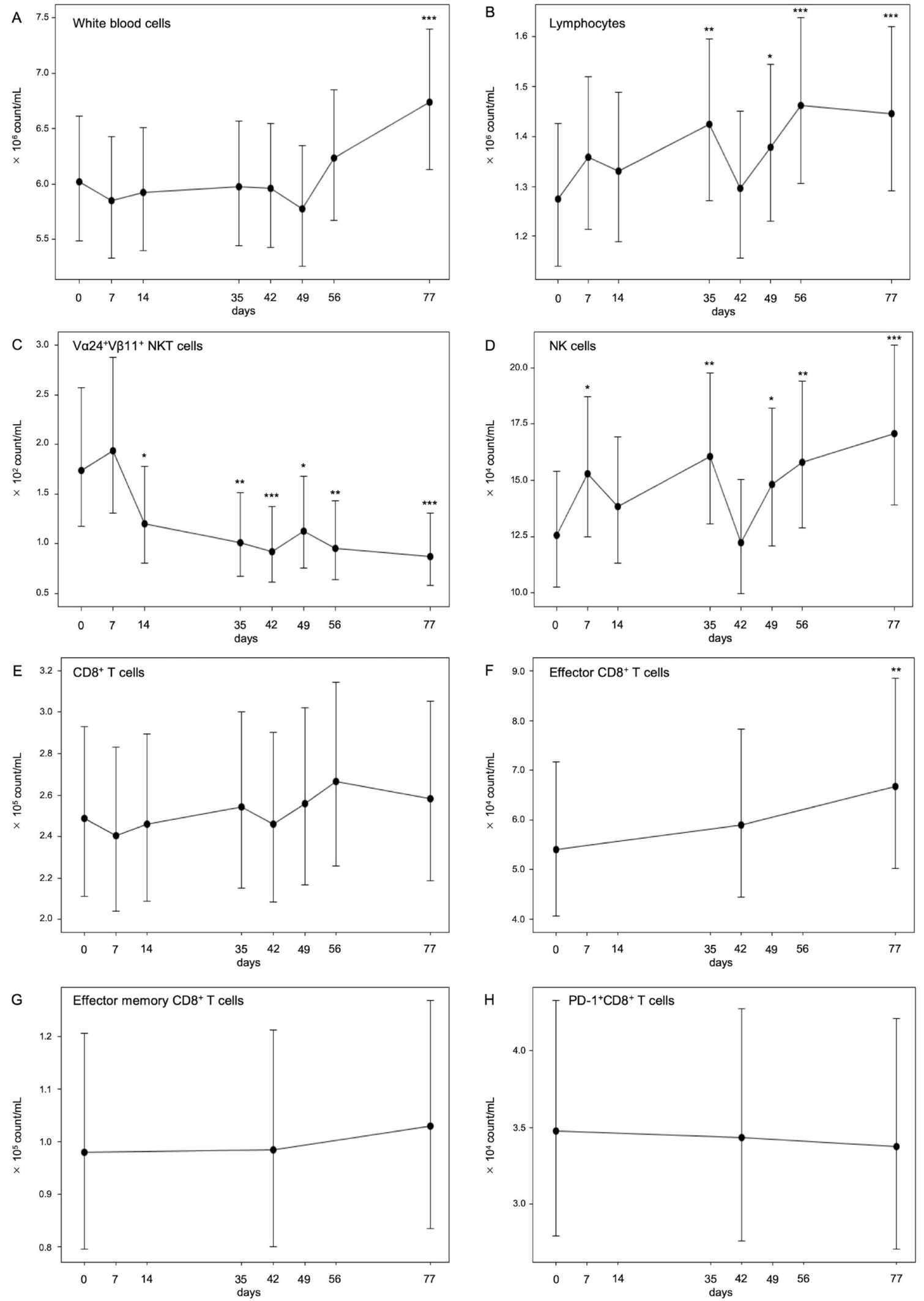

Figure 3 Numbers of circulating lymphocytes during treatment. The absolute numbers of white blood cells (A) and lymphocytes (B) were counted by clinical blood tests. The percentages of peripheral blood V $\alpha 24+V \beta 11+i N K T$ cells $(C)$, CD56+CD3- NK cells (D), CD3+CD8+ T cells (E), CD45RA-CCR7+ effector CD8+ T cells (F), CD45RA-CCR7- effector memory CD8+ T cells $(G)$, and PD-1+CD8+ cells $(H)$ during treatment were assessed by flow cytometry analysis, and the absolute numbers of these cells were calculated using full blood counts. The linear mixed effect model for repeated measurements was used to estimate the geometric mean, $\mathrm{SE}$, and $95 \% \mathrm{Cl}$ of the mean of each measuring point of immune monitoring, which can address all available post-baseline data. ${ }^{*} \mathrm{p}<0.05,{ }^{* *} \mathrm{p}<0.01,{ }^{* * *} \mathrm{p}<0.001$. NK, natural killer. 

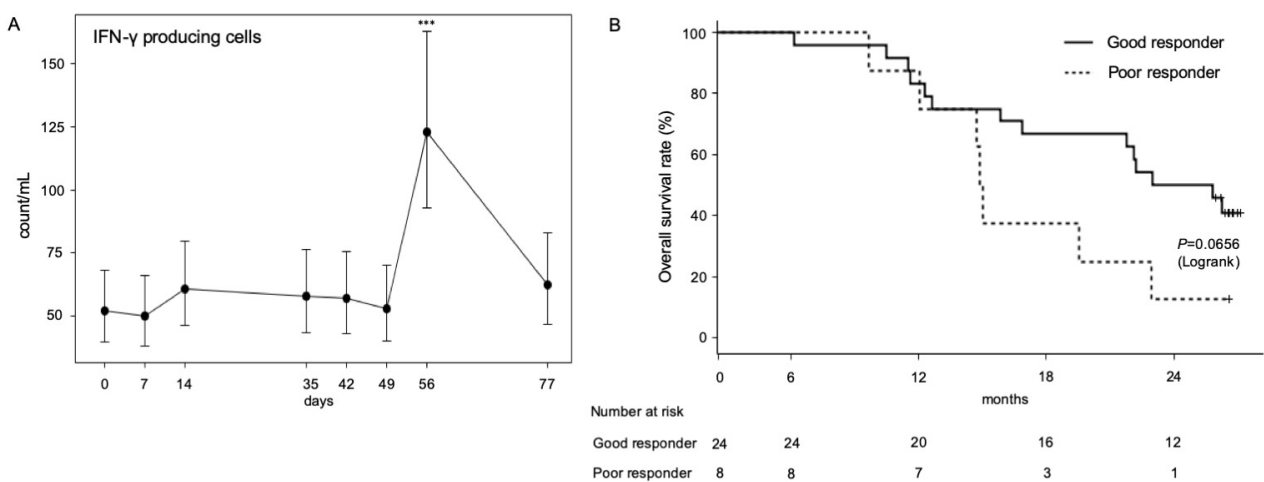

Figure 4 Numbers of circulating lymphocytes during treatment. (A) The number of IFN- $\gamma$-producing cells after $\alpha \mathrm{GalCer}$ restimulation was assessed by ELISPOT assay. The linear mixed effect model for repeated measurements was used to estimate the geometric mean, SE, and $95 \% \mathrm{Cl}$ of the mean of each measuring point of immune monitoring, which can address all available post-baseline data; ${ }^{* \star} p<0.001$. (B) A comparison of overall survival of good responders with increased IFN- $\gamma$ producing cells $(n=24)$ and poor responders $(n=8)$. ELISPOT, enzyme-linked immunospot; IFN- $\gamma$, interferon- $\gamma$.

administration of $\alpha$ GalCer-pulsed APCs is acceptable with regard to toxicity and safety.

We detected that the number of cells producing IFN- $\gamma$ increased by more than 1.9-fold in 24 out of 32 patients who received $\alpha$ GalCer-pulsed APCs. These good responders showed a tendency to have a longer MST and higher 2-year survival rates than the poor responders (figure 2B), confirming the findings of our previous study. ${ }^{22}$ It might be argued that the correlation between the ability to induce increased IFN- $\gamma$-producing cells and patient survival might merely reflect the patients' original immune statuses and be unrelated to the cell therapy. However, even the MST of the poor responder group, of around 15 months, seemed to be an acceptable outcome compared with various types of chemotherapies as second-line treatment for NSCLC, as described above. Therefore, poor responders were not likely to consist of patients with a bad immunological prognosis, which could explain the early death rate and rapid disease progression due to a failure to induce IFN- $\gamma$-producing cells. Consequently, we have not considered the increased numbers of IFN- $\gamma$-producing cells in PBMCs as an influence on the individual immune status alone. We expect IFN- $\gamma$-producing cells to be a promising biomarker for the prediction of the clinical course in response to $\alpha \mathrm{GalCer}$ pulsed APC administration.

Because it is a disadvantage that a biomarker cannot be obtained prior to treatment, biomarkers that can be evaluated before treatment are desirable. Several candidates for predictive biomarkers for anti-PD-1/PD-L1 immunotherapy have been reported, ${ }^{35}$ such as PD-L1 tumor expression and PD-1 lymphocyte expression,,$^{30} 36$ HLA loss, ${ }^{38}$ tumor mutational burden, ${ }^{39-41}$ an active immune microenvironment, ${ }^{42}$ and the phenotype of peripheral blood immune cells. ${ }^{43}$ In our study, the numbers of NKT, $\mathrm{NK}$, and IFN- $\gamma$-producing cells before treatment were not related to the therapeutic effect and survival (data not shown). Further analysis will be necessary to analyze the association between these factors and the clinical response to this treatment.
Various changes in the immune cells in the peripheral blood were recognized. First, transient increases in IFN- $\gamma$-producing cells during the protocol treatment were revealed. Previously, we showed that the IFN- $\gamma$-producing cells induced after in vitro $\alpha$ GalCer restimulation were NK and iNKT cells but not T cells in this assay system. ${ }^{20} 44$ Therefore, increases in IFN- $\gamma$-producing cells might be associated with the increase in iNKT or NK cells. According to our result, NK cells increased and iNKT cells decreased in peripheral blood after the administration of $\alpha$ GalCer-pulsed APCs. This result was compatible with our previously reported data that $\alpha$ GalCer-pulsed APC administration induced the dramatic infiltration and activation of iNKT cells in tumor lesions, although iNKT cells were not increased in peripheral blood. ${ }^{45}$ Furthermore, even in early-stage lung cancer, it was reported that the ratio of NK cells in tumor-infiltrating lymphocytes was low and the cytotoxic activity of NK cells that had infiltrated the cancer was also reduced. ${ }^{46} \mathrm{NK}$ cells activated by $\alpha$ GalCer-pulsed APC administration might be incapable of moving effectively to tumors from the peripheral blood. Second, although the number of $\mathrm{CD} 8+\mathrm{T}$ cells did not change during the protocol treatment, effector CD8+ T cells increased on day 77. It might be possible that the IFN- $\gamma$-producing cells activated CD8+ T cells and that the effect of this activation lasted a long time; however, it could not be verified because the number of cells changed slightly. Further experiments are needed to confirm this effect on the activation of cytotoxic T cells.

The relevant limitations of this monocentric prospective study are the single-arm design and the relatively small number of patients. Moreover, there was no provision for post-treatment, which may have affected survival after each therapy. Five of seven patients with EGFR mutations were subjected to EGFR-TKI therapy with a relatively high therapeutic effect in pretreatment. The other two patients were treated with EGFR-TKIs after $\alpha$ GalCer-pulsed APC treatment, which may have affected their prognosis (667 days and 810 days), although the sample size was not large enough to improve the MST of this cohort. Further 
investigations are required to provide robust evidence on the potential impact of these problems.

\section{CONCLUSIONS}

$\alpha$ GalCer-pulsed APC immunotherapy, which induces the activation of endogenous iNKT cells and iNKT celldependent responses, is accompanied by prolonged OS. The increase in IFN- $\gamma$-producing cells in PBMCs is associated with prolonged MST, and thus these results are encouraging and warrant further evaluation in a randomized phase III trial to demonstrate the survival benefit of this immunotherapy.

Acknowledgements The authors are grateful to Hiromi Chiku, Emi Sato, Ayumi Kuboyama-Hayashi, and Saori Tagi for their excellent technical assistance in cell culture. We thank all the nurses and staff surgeons in the Department of the General Thoracic Surgery, Chiba University Hospital, Chiba, Japan, for their excellent help with patient care and their continuous support. We also thank H. Nikki March, $\mathrm{PhD}$, from Edanz Group (www.edanzediting.com/ac) for editing a draft of this manuscript.

Funding This work was supported by grants from the Ministry of Health, Labor, and Welfare (Japan) (the Health and Labor Sciences Research Grant: H24-Hisaichiiki-Shitei-013) and the Japan Agency for Medical Research and Development (JP16lk0201013).

Competing interests None declared.

Patient consent for publication Not required.

Ethics approval The protocol was approved by the Institutional Ethics Committee (No. 1124) and the Ministry of Health, Labor and Welfare as Advanced Medical Technology. Written informed consent was obtained from all the patients before undergoing a screening evaluation to determine eligibility.

Provenance and peer review Not commissioned; externally peer reviewed.

Data availability statement Data are available upon reasonable request. The data sets used and/or analyzed during the current study are available from the corresponding author on reasonable request based on the condition that IRB and MTA could be approved from the institutions.

Open access This is an open access article distributed in accordance with the Creative Commons Attribution Non Commercial (CC BY-NC 4.0) license, which permits others to distribute, remix, adapt, build upon this work non-commercially, and license their derivative works on different terms, provided the original work is properly cited, appropriate credit is given, any changes made indicated, and the use is non-commercial. See http://creativecommons.org/licenses/by-nc/4.0/.

\section{ORCID iD}

Shinichiro Motohashi http://orcid.org/0000-0002-9332-3129

\section{REFERENCES}

1 Somasundaram A, Burns TF. The next generation of immunotherapy: keeping lung cancer in check. J Hematol Oncol 2017;10:87.

2 Garon EB. Current perspectives in immunotherapy for non-small cell lung cancer. Semin Oncol 2015;42 Suppl 2:S11-18.

3 Chen DS, Mellman I. Elements of cancer immunity and the cancerimmune set point. Nature 2017;541:321-30.

4 Kawano T, Cui J, Koezuka Y, et al. Cd1D-Restricted and TCRmediated activation of Valpha14 NKT cells by glycosylceramides. Science 1997;278:1626-9.

5 Salio M, Silk JD, Jones EY, et al. Biology of CD1- and MR1-restricted T cells. Annu Rev Immunol 2014;32:323-66.

6 Altman JB, Benavides AD, Das R, et al. Antitumor responses of invariant natural killer T cells. J Immunol Res 2015;2015:1-10.

7 Motohashi S, Okamoto Y, Yoshino I, et al. Anti-Tumor immune responses induced by iNKT cell-based immunotherapy for lung cancer and head and neck cancer. Clin Immunol 2011;140:167-76.

8 Rossjohn J, Pellicci DG, Patel O, et al. Recognition of CD1drestricted antigens by natural killer T cells. Nat Rev Immunol 2012;12:845-57.
9 Taniguchi M, Seino K-I, Nakayama T. The NKT cell system: bridging innate and acquired immunity. Nat Immunol 2003;4:1164-5.

10 Matsuda JL, Mallevaey T, Scott-Browne J, et al. CD1d-restricted iNKT cells, the 'Swiss-Army knife' of the immune system. Curr Opin Immunol 2008;20:358-68.

11 Fujii S, Motohashi S, Shimizu K, et al. Adjuvant activity mediated by iNKT cells. Semin Immunol 2010;22:97-102.

12 Toura I, Kawano T, Akutsu Y, et al. Cutting edge: inhibition of experimental tumor metastasis by dendritic cells pulsed with alphagalactosylceramide. J Immunol 1999;163:2387-91.

13 Fujii S-ichiro, Shimizu K, Kronenberg M, et al. Prolonged IFN-gamma-producing NKT response induced with alphagalactosylceramide-loaded DCs. Nat Immunol 2002;3:867-74.

14 Nieda M, Okai M, Tazbirkova A, et al. Therapeutic activation of Valpha24+Vbeta11+ NKT cells in human subjects results in highly coordinated secondary activation of acquired and innate immunity. Blood 2004;103:383-9.

15 Chang DH, Osman K, Connolly J, et al. Sustained expansion of NKT cells and antigen-specific T cells after injection of alpha-galactosylceramide loaded mature dendritic cells in cancer patients. J Exp Med 2005;201:1503-17.

16 Richter J, Neparidze N, Zhang L, et al. Clinical regressions and broad immune activation following combination therapy targeting human NKT cells in myeloma. Blood 2013;121:423-30.

17 Exley MA, Friedlander P, Alatrakchi N, et al. Adoptive transfer of invariant NKT cells as immunotherapy for advanced melanoma: a phase I clinical trial. Clin Cancer Res 2017;23:3510-9.

18 Godfrey DI, Le Nours J, Andrews DM, et al. Unconventional T cell targets for cancer immunotherapy. Immunity 2018;48:453-73.

19 Ishikawa A, Motohashi S, Ishikawa E, et al. A phase I study of alphagalactosylceramide (KRN7000)-pulsed dendritic cells in patients with advanced and recurrent non-small cell lung cancer. Clin Cancer Res 2005;11:1910-7.

20 Motohashi S, Ishikawa A, Ishikawa E, et al. A phase I study of in vitro expanded natural killer T cells in patients with advanced and recurrent non-small cell lung cancer. Clin Cancer Res 2006;12:6079-86.

21 Uchida T, Horiguchi S, Tanaka Y, et al. Phase I study of alphagalactosylceramide-pulsed antigen presenting cells administration to the nasal submucosa in unresectable or recurrent head and neck cancer. Cancer Immunol Immunother 2008;57:337-45.

22 Motohashi S, Nagato K, Kunii N, et al. A phase I-II study of alphagalactosylceramide-pulsed IL-2/GM-CSF-cultured peripheral blood mononuclear cells in patients with advanced and recurrent non-small cell lung cancer. J Immunol 2009;182:2492-501.

23 Kunii N, Horiguchi S, Motohashi S, et al. Combination therapy of in vitro-expanded natural killer T cells and alpha-galactosylceramidepulsed antigen-presenting cells in patients with recurrent head and neck carcinoma. Cancer Sci 2009;100:1092-8.

24 Yamasaki K, Horiguchi S, Kurosaki M, et al. Induction of NKT cellspecific immune responses in cancer tissues after NKT cell-targeted adoptive immunotherapy. Clin Immunol 2011;138:255-65.

25 Takami M, Ihara F, Motohashi S. Clinical application of iNKT cellmediated anti-tumor activity against lung cancer and head and neck cancer. Front Immunol 2018;9:9.

26 Groome PA, Bolejack V, Crowley JJ, et al. The IASLC lung cancer staging project: validation of the proposals for revision of the $T$, $\mathrm{N}$, and $\mathrm{M}$ descriptors and consequent stage groupings in the forthcoming (seventh) edition of the TNM classification of malignant tumours. J Thorac Oncol 2007;2:694-705.

27 Mukohara T, Takeda K, Miyazaki M, et al. Japanese experience with second-line chemotherapy with low-dose $(60 \mathrm{mg} / \mathrm{M} 2)$ docetaxel in patients with advanced non-small-cell lung cancer. Cancer Chemother Pharmacol 2001;48:356-60.

28 Borghaei H, Paz-Ares L, Horn L, et al. Nivolumab versus docetaxel in advanced Nonsquamous non-small-cell lung cancer. N Engl J Med 2015;373:1627-39

29 Brahmer J, Reckamp KL, Baas P, et al. Nivolumab versus docetaxel in advanced squamous-cell non-small-cell lung cancer. $N$ Engl J Med 2015;373:123-35.

30 Reck M, Rodríguez-Abreu D, Robinson AG, et al. Pembrolizumab versus chemotherapy for PD-L1-positive non-small-cell lung cancer. N Engl J Med 2016;375:1823-33.

31 Fehrenbacher L, Spira A, Ballinger M, et al. Atezolizumab versus docetaxel for patients with previously treated non-small-cell lung cancer (poplar): a multicentre, open-label, phase 2 randomised controlled trial. Lancet 2016;387:1837-46.

32 Garon EB, Ciuleanu T-E, Arrieta O, et al. Ramucirumab plus docetaxel versus placebo plus docetaxel for second-line treatment of stage IV non-small-cell lung cancer after disease progression on platinum-based therapy (REVEL): a multicentre, double-blind, randomised phase 3 trial. Lancet 2014;384:665-73. 
33 Reck M, Kaiser R, Mellemgaard A, et al. Docetaxel plus nintedanib versus docetaxel plus placebo in patients with previously treated non-small-cell lung cancer (LUME-Lung 1): a phase 3, double-blind, randomised controlled trial. Lancet Oncol 2014;15:143-55.

34 Gridelli C, Ascierto PA, Grossi F, et al. Second-Line treatment of advanced non-small cell lung cancer Non-oncogene addicted: new treatment algorithm in the era of novel immunotherapy. Curr Clin Pharmacol 2018;13:76-84.

35 Maleki Vareki S, Garrigós C, Duran I. Biomarkers of response to PD-1/PD-L1 inhibition. Crit Rev Oncol Hematol 2017:116:116-24.

36 Patel SP, Kurzrock R. Pd-L1 expression as a predictive biomarker in cancer immunotherapy. Mol Cancer Ther 2015;14:847-56.

37 Shukuya T, Carbone DP. Predictive markers for the efficacy of antiPD-1/PD-L1 antibodies in lung cancer. J Thorac Oncol 2016;11:976-88.

38 McGranahan N, Rosenthal R, Hiley CT, et al. Allele-Specific HLA loss and immune escape in lung cancer evolution. Cell 2017; 171:1259-71.

39 Rizvi NA, Hellmann MD, Snyder A, et al. Cancer immunology. mutational landscape determines sensitivity to PD-1 blockade in non-small cell lung cancer. Science 2015;348:124-8.
40 McGranahan N, Furness AJS, Rosenthal R, et al. Clonal neoantigens elicit T cell immunoreactivity and sensitivity to immune checkpoint blockade. Science 2016;351:1463-9.

41 Yarchoan M, Hopkins A, Jaffee EM. Tumor mutational burden and response rate to PD-1 inhibition. N Engl J Med 2017;377:2500-1.

42 R-R J, Chasalow SD, Wang L, et al. An immune-active tumor microenvironment favors clinical response to ipilimumab. cancer immunology. Immunotherapy 2012;61:1019-31.

43 Krieg C, Nowicka M, Guglietta S, et al. High-Dimensional single-cell analysis predicts response to anti-PD-1 immunotherapy. Nat Med 2018;24:144-53.

44 Motohashi S, Nakayama T. Clinical applications of natural killer T cell-based immunotherapy for cancer. Cancer Sci 2008;99:638-45.

45 Nagato K, Motohashi S, Ishibashi F, et al. Accumulation of activated invariant natural killer T cells in the tumor microenvironment after $\alpha$-galactosylceramide-pulsed antigen presenting cells. J Clin Immunol 2012;32:1071-81.

46 Lavin Y, Kobayashi S, Leader A, et al. Innate immune landscape in early lung adenocarcinoma by paired single-cell analyses. Cell 2017;169:750-65. 